\title{
A leitura do Supremo Tribunal Federal sobre o sistema recursal e o início da execução da pena: a pauperização do comparatismo à brasileira
}

\author{
Supreme Court case law on the appeal system and the beginning of \\ sentencing executing: the poverty of Brazilian comparative law
}

\section{Fauzi Hassan Choukr ${ }^{1}$}

Faculdades de Campinas/SP

fhchoukr@gmail.com

http://lattes.cnpq.br/8988661367547284

https://orcid.org/0000-0002-6433-6203

\begin{abstract}
Resumo: O presente artigo almeja discutir o emprego, pelo STF, do método comparativo como sustentação da sua racionalidade no enfrentamento do tema do início da execução da pena antes do trânsito em julgado da sentença condenatória. Após uma análise do itinerário da compreensão da Corte sobre a matéria será apreciada a forma como o emprego do comparatismo se deu na mais recente decisão sobre a matéria, empregado que foi com frágeis básicas
\end{abstract}

1 Pós-Doutorado pela Universidade de Coimbra (2012/2013). Doutorado (1999) e Mestrado (1994) em Direito Processual Penal pela Universidade de São Paulo. Especializado em Direitos Humanos pela Universidade de Oxford (New College; 1996) e em Direito Processual Penal pela Universidade Castilla la Mancha (2007). Capacitação profissional para o sistema acusatório junto ao CEJA- Centro de Estudos Jurídicos das Américas (OEA), Chile, 2016; Pesquisador convidado do Instituto Max Planck para direito penal estrangeiro, internacional e criminologia (1997 a 2008): Pesquisador convidado do Collège de France, cátedra sob regência da Profa. Mirreile Delmas- Marty (2005 a 2011). Membro da Associação Internacional de Direito Penal (AIDP); do Instituto Panamericano de Direito Processual; da Associação Brasileira de Direito Processual (ABDPro); do Instituto Brasileiro de Direito Processual Penal (IBRASPP); do Instituto Brasileiro de Ciências Criminais (IBCCrim) Pesquisas concentradas nos seguintes temas: direitos fundamentais e sistema penal; internacionalização de direitos e globalização econômica; justiça de transição. Promotor de Justiça no Estado de São Paulo (desde 1989). 
metodológicas, passando a servir como argumento de autoridade para sustentá-los.

Palavras-Chave: Direito comparado; STF; Duplo Grau; Início execução de pena.

ABSTRACT: This paper aims to discuss the use, by the Supreme Brazilian Court, of the comparative method as a basis for its rationality about the moment when the penal sentencing must be executed and the penalty must be executed. After an analysis of the ways of the Court's understanding on that subject, it will be appreciated how the comparative law was employed in the most recent decision on the subject, which was used with fragile methodological basis, so being used as an authoritative argument to support them.

KeY-Words: Comparative law; Brazilian Supreme Courte case law; judicial review; beginning of enforcement of a penalty.

SUMÁRIO: Introdução. 1. O cenário constitucional. 2. A construção da racionalidade decisória do STF no tema proposto: os dois primeiros "movimentos" e o emprego do comparatismo. 2.1. O apego ao sistema jurídico anterior a 1988. 3. O segundo movimento: a sustentação constitucional convencional para superação do entendimento anterior. 4. O terceiro movimento e a fragilidade argumentativa. 4.1. O emprego da argumentação comparada. Conclusões.

\section{INTRODUÇÃO}

O presente texto tem como objetivo demonstrar a precariedade do uso do método comparado, pelo Supremo Tribunal Federal, na construção de sua compreensão sobre a relação entre presunção de inocência e o início da execução da pena, também chamada de "execução provisória" da sentença penal.

Sem buscar a análise individualizada de cada julgado daquela Corte sobre o tema desde 1988, a ênfase será dada ao itinerário jurisprudencial que culmina no quanto decidido no HC $126.292^{2}$ e o que ali se utilizou a título de argumentação comparada como método para sustentar votos proferidos.

2 BRASIL. STF. HC 126292, Relator(a): Min. Teori Zavascki, Tribunal Pleno, julgado em 17/02/2016, processo eletrônico dje-100 divulg 16-05-2016 
Como instrumento crítico ao emprego do comparatismo na forma apresentada pelo STF será empregada a compreensão metodológica encontrada nas obras de Eser e Legrand pelas quais se supera a mera invocação normativa a título de método de Direito comparado para enfatizar o conceito de cultura jurídica comparada, compreensiva dos aspectos normativos em sentido estrito, da aplicação prática respectiva e da cultura técnica que o analisa. ${ }^{3}$

Assim, como pontua Legrand "trata-se de abordar uma lei ou uma decisão jurisprudencial lembrando a todo momento que essa lei ou essa decisão "não caiu do céu" para dizer as coisas em uma linguagem "popular". Pelo contrário, a diferença está embutida em uma cultura. Ela se explica dessa forma à luz de uma cultura e só pode ser justificada à luz dessa mesma cultura".

Essa concepção do comparatismo busca evitar não apenas a fragilização do método como, também, o mero mimetismo jurídico ou, em outra linguagem, o puro transplante de texto de lei desprovido de qualquer racionalidade desde sua fonte de origem até o ordenamento onde é empregado.

Ademais, o comparatismo como método exige seleção criteriosa de ordenamentos a serem utilizados na comparação, quando não a própria identificação de agrupamentos jurídicos com determinadas características que os envolvem em famílias jurídicas viabilizando, num primeiro momento, a macrocomparação para, em outra dimensão, comparar-se temas específicos, a denominada microcomparação ${ }^{5}$.

E, como passo essencial o comparatismo também exige que o objeto da comparação seja fracionado em seus elementos estruturais e, em relação a cada um deles, deve haver a análise específica.

public 17-05-2016.

3 CRUZ, Peter de, A Modern Approach to Comparative Law, Boston, Kluwer, 1993, p. 15, apud ENRÍQUEZ, David. Interculturalismo y transdisciplinariedad: coordenadas en el mapa del derecho comparado sustentable. Boletín mexicano de derecho comparado, v. 44, n. 132, p. 1085-1126, 2011, p. 6.

4 LEGRAND, Pierre. Como ler o Direito Estrangeiro. São Paulo: Contracorrente, 2018, p. 65. Na mesma linha de análise ENRÍQUEZ, David. Interculturalismo y transdisciplinariedad: coordenadas en el mapa del derecho comparado sustentable. Boletín mexicano de derecho comparado, v. 44, n. 132, p. 10851126, 2011.

5 A ver o quanto afirmado por MOURA VICENTE, Dário - Direito Comparado - Volume I - Introdução e Parte Geral, Almedina, Coimbra, 2008, p. 19. 
Assim, adiantando um tópico que será particularmente abordado, falar em coisa julgada exige a compreensão dessa expressão no direito que se quer usar como fonte de comparação, não sendo possível a priori, conceber que o que se entende por coisa julgada no Direito brasileiro assim o seja, de forma idêntica, em outro ordenamento.

A escolha da crítica ao tema em concreto decidido pelo STF repousa na sua repercussão multidimensional no cenário jurídico posto que não se cinge à seara penal. Com efeito, antecipar os efeitos da execução da pena antes do trânsito em julgado - e usando o comparatismo como forte arrimo metodológico para tanto - possui repercussões desde as consequências civis em sentido estrito até mesmo aquelas de fruição de direitos da cidadania, como a capacidade eleitoral, sendo que nenhuma dessas dimensões foi sequer tangenciada quando a Corte resolveu empregar o comparatismo.

Inicia-se com o percurso traçado pela Constituição da República sobre o tema da vinculação da presunção de inocência com o trânsito em julgado para, na sequência, enlaçar a matéria com a postura do STF e o emprego do comparatismo.

\section{O CENÁRIO CONSTITUCIONAL}

A Constituição da República determina que a execução da pena está ligada ao trânsito em julgado da sentença condenatória momento em que a pessoa acusada decai do seu direito à presunção de inocência sobre os fatos que lhe foram imputados para, então, ter início a execução da sanção.

A redação inovadora para os parâmetros constitucionais brasileiros claramente aponta no seu art. 5\%, LVII, que "ninguém será considerado culpado até o trânsito em julgado de sentença penal condenatória” e, por ela, se deveria ter por superada toda uma ordem anterior que admitia inúmeras espécies de prisão prévias ao julgamento transitado em julgado sem considerá-las, contudo, no contexto cautelar. Eram modalidades de prisões orientadas por fases processuais e aplicadas de forma automática.

A nova ordem constitucional, a qual deve ser acrescida pela ordem convencional em 1992 e reforçada, em 1998, com a aceitação, pelo 
Brasil, da competência da Corte Interamericana de Direitos Humanos não foi capaz de consolidar a modificação desse arcabouço jurídico e o que se viu nesse tema, em especial, foi a manutenção de todo um cenário argumentativo preexistente acentuado por argumentos metajurídicos que flertam com práticas políticas populistas em nome de uma difusa "eficiência" punitiva. ${ }^{6}$

Enfrentando a explícita redação constitucional mereceu destaque uma insistente divisão entre "presunção de inocência" e "presunção de não culpabilidade" , aquela prevista no Direito Internacional Público e, a última, presente no texto constitucional, destacando-se que na expressão "não culpabilidade" constam orientações as quais induzem que "a tutela do interesse social de repressão à delinquência deveria preponderar sobre o interesse individual de liberdade." 8

A importância dessa distinção é trabalhada em países que guardam a dicotomia apontada (não culpabilidade $\mathrm{x}$ inocência) entre seus textos internos (Constituição) e externos (Convenções de Direitos Humanos) aos quais se encontram vinculados, como é o caso italiano.

6 Inversamente ao quanto apontado por Damaška quando afirma que os sistemas processuais são pressionados para que se modifiquem pela necessidade de uma maior "eficiência" ou para atender estândares protetivos de direitos fundamentais (e nesse ponto se aproxima aos "dois modelos" de sistema penal proposto por Packer), a orientação jurisprudencial manteve seu olhar no passado em busca de um pseudo ideal de eficiência, atuando como um verdadeiro aríete hermenêutico contra o texto constitucional então recém promulgado. A propósito do quanto aqui afirmado ver DAMAŠKA, Mirjan. Aspectos globales de la reforma del proceso penal. Reformas a la Justicia penal en las Américas. www. dplf. org/Fundación para el debido proceso legal, 2000; PACKER, Herbert L. Two models of the criminal process. U. Pa. L. Rev., v. 113, p. 1, 1964.

7 Sobre o tema ver na doutrina nacional, entre outros, CARVALHO, Luis Gustavo Grandinetti Castanho de. Princípio da presunção de inocência ou da não-culpabilidade. In: CARVALHO, Luis Gustavo Grandinetti Castanho de. Processo penal e constituição: princípios constitucionais do processo penal. 4. ed. Rio de Janeiro: Lumen Juris, 2006.

8 MIRZA, F.. Processo Justo: O ônus da Prova à Luz dos Princípios da Presunção de Inocência e do in dubio pro reo. In: Cleber Francisco Alves; Sergio de Souza Salles. (Org.). Justiça, Processo e Direitos Humanos - Coletânea de Estudos Multidisciplinares. 1 ed.Rio de Janeiro: Lumen Juris, 2009, p. 79-96. 
Afirma-se, quanto ao Direito italiano, que "il problema nasce anche dal fatto che le due formulazioni, contrariamente da quanto si possa essere indotti a ritenere, non sono sinonime, ma possiedono sfumature loro proprie facenti sì che sostenerne una comporti modificare il trattamento da offrire all'imputato", superando, assim, a posição de suposta neutralidade sustentada por Leone e Manzini ${ }^{10}$ que mascara o "discurso antiliberal da Escola Técnico-Jurídica, de base político-fascista, [que] foi determinante na elaboração do art. 27 da Constituição Italiana de 1948". ${ }^{11}$

A doutrina distintiva entre essas duas expressões e que é tomada como norteadora de um determinado "saber processual" deita suas raízes no pós II Guerra Mundial (Leone escreve em 1947 e Manzini é seu contemporâneo sustentando a dicotomia) e as críticas de Illuminati são datadas do final dos anos 1970 e publicadas no início dos anos 1980 assim como as de Sabbatini, quem escreve em 1976, portanto em períodos nos quais a interrelação de fontes normativas não era concebida da forma como é hoje, obrigando uma revisão conceitual profunda do conceito de poder estatal, soberania e produção normativa.

Essa diferenciação, cujas matrizes político-jurídicas se encontram amplamente superadas pela construção contemporânea do Estado de Direito, ${ }^{12}$ permite uma expansão da "objetificação" da pessoa submetida à persecução e não encontra mais guarida em textos teóricos mesmo no país usado como paradigma da preconizada distinção, seja porque dáse a supremacia da maximização dos direitos fundamentais ou porque passou-se a assimilar tais expressões em favor da mais protetiva, a da presunção de inocência.

No caso brasileiro importa saber que no Anteprojeto Constitucional, elaborado pela Comissão Provisória de Estudos Constitucionais, instituída

9 BATIA, G. e PIZZO, A. La tutela dell' imputato - Saggio storico- concettuale, PAULESU, Pier Paolo. La presunzione di non colpevolezza dell'imputato, 30, Torino: Giappichelli, 2009, p. 30-50. Numa tradução livre: "O problema nasce também do fato que as duas formulações, contrariamente ao quanto se pode levar a crer, não são sinônimas, mas possuem contornos próprios de modo que sustentar uma delas comporta na modificação do tratamento conferido ao imputado" BATIA, op. cit.

11 MIRZA, op cit.

12 Para o direito italiano ver a crítica de ILLUMINATI, Giulio. La presunzione d'innocenza dell 'imputato. Bolonha: Zanichelli, 1984, p. 21. 
pelo Decreto $\mathrm{n}^{\circ}$ 91.450, de 18 de julho de 1985 havia, no então artigo 43 § $7^{\circ}$, a previsão de presunção de inocência: "Presume-se inocente todo acusado até que haja declaração judicial de culpa”, alterado que foi ao longo dos trabalhos constituintes até alcançar a redação final que desde então possui.

Mas essa redação, que não se manteve no texto constitucional finalmente promulgado e que privilegiava a presunção de inocência, acaba por ser incorporado definitivamente ao direito interno quando se observa que pela interrelação de fontes normativas, a aceitação brasileira do sistema interamericano de direitos humanos, constituído pela estrutura bifásica OEA - Corte Interamericana de Direitos Humanos ${ }^{13}$ impõe a adoção normativa mais protetiva porquanto se trata da tutela de direitos fundamentais, solução à sombra da qual inúmeras discussões teóricas precedentes, embora vistosas do ponto de vista estritamente técnico, perdem seu sentido político e, portanto, sua própria densidade teórica.

\section{A CONSTRUÇÃo dA RACIONALIDAdE DECISÓRIA do STF NO TEMA PROPOSTO: OS DOIS PRIMEIROS "MOVIMENTOS" E O EMPREGO DO COMPARATISMO}

No arco temporal que vai de 1988 a 2016 dois grandes momentos podem ser identificados na abordagem jurídica do tema "início da execução da pena": um, mais longo, vai de 1988 a 2009, portanto duas décadas nas quais insistiu-se numa hermenêutica lastreada na literalidade do CPP em detrimento do marco constitucional-convencional; outra, de 2009 a 2016, na qual aconteceu, ao menos do ponto majoritário no STF, a prevalência constitucional-convencional sobre as raízes codificadas.

Ambos momentos apresentaram algum relacionamento com o comparatismo: no primeiro, o emprego comparado foi razoavelmente tímido e desprovido de ambições maiores de argumento de autoridade; no segundo, o comparatismo já surge como argumento de autoridade para desautorizar a interpretação constitucional que se construía e que tem como consequência, portanto, a prevalência do Código de Processo Penal sobre o marco constitucional-convencional.

13 CONSTANTINO, Giuseppe Luigi Pantoja. Sistema Interamericano de Direitos Humanos: breves linhas sobre a Comissão e a Corte Interamericana de Direitos Humanos. Conteúdo Jurídico, Brasília-DF: 20 dez. 2014 
Nesse segundo momento, a título de comparatismo passa-se a incorrer na limitação metodológica criticada neste trabalho, tratando a título de comparatismo a mera indicação de textos normativos a partir dos quais são alcançadas rotulações genéricas sobre o funcionamento da existência de uma suposta execução antecipada da pena em determinado país.

\subsection{O APEGO AO SISTEMA JURÍDICO ANTERIOR A $1988^{14}$}

Ao longo de vinte anos, o STF repetiu, sem qualquer inflexão à base constitucional-convencional, a estrutura anterior lastreada na forma como o CPP organizava as hipóteses de prisão sem condenação definitiva, algumas delas de incidência automática. ${ }^{15}$

Mas esse desapego constitucional-convencional tinha uma dimensão prática: a insuficiência da estrutura judiciária em julgar definitivamente processos dentro de um prazo razoável.

As distorções se avolumavam (e ainda assim o é) para criar casos nos quais presos sem condenação definitiva aguardavam largo tempo o

14 Para uma visão sobre o tema ver BRANDÃO, João Pedro Pereira. A execução antecipada da pena nos tribunais superiores brasileiros: os limites da garantia constitucional da presunção de não-culpabilidade. Revista Brasileira de Ciências Criminais, São Paulo, v. 17, n. 80, p. 150-207., set./out. 2009.

15 Na redação original do Código havia a previsão da prisão automática em função de pena em abstrato cominada a determinado crime de acordo com o Art. 312: "A prisão preventiva será decretada nos crimes a que for cominada pena de reclusão por tempo, no máximo, igual ou superior a dez anos”. Essa prisão sem fundamento cautelar projetava-se em todos os ritos, inclusive o do júri, criando, quando da pronúncia, a possibilidade de uma prisão automática, situação apenas modificada pela chamada "Lei Fleury", a Lei 5941/1973 que modificou a redação original do Art. 408 do CPP para prever que: "Se o juiz se convencer da existência do crime e de indícios de que o réu seja o seu autor, pronuncia-lo-á, dando os motivos do seu convencimento. ... § $2^{\circ}$ Se o réu for primário e de bons antecedentes, poderá o juiz deixar de decretar-lhe a prisão ou revogá-la, já se encontre preso. Além disso, havia a manutenção automática na prisão mesmo diante da sentença condenatória recorrível a teor do art. 393 que assim dispunha: "São efeitos da sentença condenatória recorrivel: I - ser o réu preso ou conservado na prisão, assim nas infrações inafiançaveis, como nas afiançaveis enquanto não prestar fiança" em combinação com o artigo Art. 318: "Em relação àquele que se tiver apresentado espontaneamente à prisão, confessando crime de autoria ignorada ou imputada a outrem, não terá efeito suspensivo a apelação interposta da sentença absolutória, ainda nos casos em que este Código lhe atribuir tal efeito”. 
julgamento do recurso interposto e lhes era negada a fruição de benefícios, somente previstos para condenados definitivos. Por esse motivo, viamse em situação amplamente desfavorável por não poderem usufruir, por exemplo, da progressão de regime.

Atenta a esta situação, prestigiosa doutrina ainda no início dos anos 1990 apontava o cenário caótico ${ }^{16}$ e pontuava que a solução encontrada na época era a de afastar explicitamente a cautelaridade ${ }^{17}$ justificando desta forma a criação de uma execução inexistente a partir da expedição de um documento igualmente não previsto em lei: a GRP - guia de recolhimento provisória ${ }^{18}$, com a qual uma pessoa presa que rigorosamente só poderia ser assim considerada com fundamento cautelar - fosse admitida como uma pessoa sentenciada para fins de obtenção de "benefícios processuais" específicos da execução da pena. ${ }^{19}$

16 SUANNES, Adauto Alonso Silvinho. Podemos falar em execução penal antecipada (jurisprudência comentada). Revista Brasileira de Ciências Criminais, São Paulo, v. 2, n. 7, p. 167-173., jul./set. 1994

17 SUANNES, op cit, neste ponto específico mencionando as falas de Afrânio Silva Jardim e Sérgio Médice (obras citadas no texto) que afastavam a natureza cautelar desse encarceramento. Além desses autores ver, no mesmo sentido, CARVALHO, Luís Gustavo Grandinetti Castanho de. O processo penal em face da Constituição, $2^{\mathrm{a}}$ edição. Rio de Janeiro: Editora Forense, 1998.

18 Neste ponto o CNJ não apenas endossou esse procedimento à margem do marco constitucional e da legalidade que dele decorre como o regulamentou por meio de Resolução gerando, inclusive, o pertinente questionamento sobre a extensão desse instrumento para legislar no campo penal. Para uma aguda crítica desse aspecto ver SOUZA, José Barcelos de. Execução provisória de pena privativa de liberdade. Revista Magister de Direito Penal e Processual Penal, Porto Alegre, v. 4, n. 19, p. 42-54., ago./set. 2007.

19 Entendimento que acabou sendo sumulado (sem efeito vinculante) pelo próprio STF: Súmulas 716 e 717 como reflexo das posições doutrinárias mencionadas, dentre elas a de KUEHNE ao citar uma vez mais Afrânio Silva Jardim e Sérgio Médici. In verbis: "Pela sua integral pertinência, remetemos ao estudo de Afrânio Silva Jardim: A prisão, em decorrência de sentença condenatória recorrível”, in Direito Processual Penal, Editora Forense, $4^{\mathrm{a}}$ edição, pág $389 / 409$, onde, na parte que nos interessa, é apresenta” da a seguinte conclusão: "O reconhecimento da natureza de execução provisória à prisão em decorrência de sentença condenatória recorrível permite ao réu se beneficiar dos direitos outorgados pela Lei de Execução Penal, mesmo antes da apreciação do seu recurso. Assim, o exercício do direito de recorrer não prejudica a situação processual do réu". Oportunas, por igual, as colocações de Sérgio de Oliveira Médici”. KUEHNE, Maurício. Revisão do decênio da reforma penal: 
Por esse viés "positivo" um instrumento legal inexistente no marco normativo e apoiado na ineficiência estrutural da Poder Judiciário em dar vazão a julgamentos de mérito no prazo razoável passou a ser defendido por segmentos acadêmicos ${ }^{20} .^{21}$

Essa construção típica de direito interno não contou, em sede de Corte Suprema, com apoio da argumentação comparada, limitando-se essa criação aos Tribunais Estaduais ou Regionais Federais. E, embora não seja tema específico deste trabalho a análise do comparatismo na doutrina da época, pode-se apenas destacar que foram raros - senão inexistentes menções comparadas a essa "execução antecipada benéfica".

\subsection{A SUPREMACIA DA LÓGICA INFRACONSTITUCIONAL SOBRE AS BASES CONSTITUCIONAIS CONVENCIONAIS}

Nesse primeiro movimento também se faz presente um argumento de direito interno que parece resumir aquilo que se desejava como um

1985-1995: considerações sobre a execução provisória da sentença penal. Faculdade de Direito de Curitiba, 1995. A afirmação deste autor é particularmente significativa do ponto de vista político pois viria a ocupar, anos depois da publicação desse artigo, a Direção do DEPEN junto ao Ministério da Justiça.

20 Também por autores de outra geração, já formados e atuantes sob o marco constitucional-convencional. A propósito ver DEZEM, Guilherme Madeira. Presunção de inocência: efeito suspensivo dos recursos extraordinário e especial e execução provisória. Revista Brasileira de Ciências Criminais, São Paulo, v. 16, n. 70, p. 269-290., jan./fev. 2008, para quem "o acusado que se encontra preso, por exemplo, tendo sido condenado e não tendo sido admitido que recorresse em liberdade, sofrerá a chamada execução provisória, o que é plenamente constitucional”. Neste trecho mescla-se a justificação cautelar da prisão com os efeitos que advêm da sentença condenatória irrecorrível, sobreposição dominante na jurisprudência mencionada neste tópico do trabalho.

${ }^{21}$ E também no campo dos precedentes. Interessante caso no TJSP demonstra que mesmo a execução provisória era vista como colidente com a Constituição e esse questionamento advinha por conta de resolução daquele Tribunal que a havia instituído: Não é inconstitucional o Provimento n ${ }^{\circ}$ 653/99 do Egrégio Conselho Superior da Magistratura Bandeirante que reconhece a execução provisória da pena, permitindo ao preso provisório a obtenção de benefícios concedidos ao condenado com sentença transitada em julgado, assegurando-lhe a garantia da reprimenda na medida correspondente à infração penal estabelecida na sentença, em respeito ao status libertatis em confronto com o jus puniendi do Estado, sem prejuízo à futura alteração por conta de eventual substituição daquela pelo v. Acórdão. TJ-SP - EP: 990091548049 SP, Relator: Willian Campos, Data de Julgamento: 24/11/2009, $4^{a}$ Câmara de Direito Criminal, Data de Publicação: 23/12/2009 
ponto central: a (in)existência de efeitos suspensivos a determinados recursos, especialmente os de natureza constitucional.

Verdadeiramente é ele que se encontra presente no leading case do STF HC 68.726 (Rel. Min. Néri da Silveira) ${ }^{22}$ e escrito a partir da redação original do Código de Processo $\mathrm{Penal}^{23}$, no qual o Relator, apoiado em texto doutrinário de 1959 (portanto trinta anos anterior ao texto constitucional), deu prevalência à estrutura infraconstitucional às bases constitucionais, tratando a prisão decorrente de sentença recorrível como algo independente, não-cautelar, e que merecia execução imediata diante da interposição de recursos sem efeito suspensivo.

Esse argumento de forte presença entre 1988 a 2009 voltaria a carga em 2016 escorado numa visão de "teoria geral do processo" e sensível à necessidade de dotar de "eficiência" o sistema processual penal, sobretudo diante do alegado número de recursos disponível às partes.

\section{O SEgUNDO MOVIMENTO: A SUSTENTAÇÃO CONSTITUCIONAL CONVENCIONAL PARA SUPERAÇÃO DO ENTENDIMENTO ANTERIOR}

Esse segundo momento se dá com o julgamento, no STF, do HC 84.078/ $\mathrm{MG}^{24}$ que nas palavras de seu Relator, o então Min. Eros Grau, "a prisão antes do trânsito em julgado da condenação somente pode ser decretada a título cautelar" e em cujo voto destaca-se a base doutrinária de

22 BRASIL. Supremo Tribunal Federal. Habeas Corpus 68726. Impte.(S) Fernando Eduardo Ayres Da Motta. Coator(A/S)(Es) Tribunal De Alçada Criminal Do Estado Do Rio De Janeiro. Pacte.(S) Marco Antonio Da Fonseca Loureiro. Relator Atual: Min. Néri da Silveira. J. em 28/06/1991. Disponível em http://portal.stf.jus.br/processos/detalhe.asp?incidente=1521108. Acesso 12/09/2018. O trecho do relator que aqui se refere está na citação de Eduardo Espínola Filho, no vol $7^{\circ}$., dos seus "Comentários ao Código de Processo Penal” que data, na edição citada, de 1959.

23 Na redação original do CPP: “Art. 637. O recurso extraordinário não tem efeito suspensivo, e uma vez arrazoados pelo recorrido os autos do traslado, os originais baixarão à primeira instância, para a execução da sentença”.

24 BRASIL. Supremo Tribunal Federal. Habeas Corpus HC 84078. Relator(a): Min. Eros Grau. Julgamento: 05/02/2009. Órgão Julgador: Tribunal Pleno. Publicação DJe-035 Divulgação em 25-02-2010. Publicação em 26-02-2010. 
direito interno ${ }^{25}$ e este referido estritamente às estruturas constitucionais brasileiras sem sequer mencionar qualquer compromisso internacional assumido pelo Brasil que diga respeito ao tema. ${ }^{26}$

Nada obstante, no voto divergente proferido pelo Min. Menezes Direito usou-se - como seria feito mais tarde - o "direito comparado" para sustentar a divergência com o Relator afirmando-se que “A prisão na pendência de recurso é admitida em sistemas de países reconhecidamente liberais, como, por exemplo, os Estados Unidos da América (Subseção "b" do § 3.582, D, Capítulo 227, Parte II, Título 18 do US Code), o Canadá (arts. 679 e 816 do Criminal Code) e a França (art. 367 do Code de Procédure Pénale). Nos Estados Unidos, o sistema é bem claro ao admitir o imediato início do cumprimento da pena, sendo certo que a interposição de recurso de revisão de que decorreria a possibilidade de alteração não é suficiente para obstar seu imediato cumprimento". ${ }^{27}$

Nesse breve trecho, destacam-se deficiências que seriam posteriormente acentuadas: a redução do comparatismo legal a menção a artigos de lei, o emprego de instrumentos jurídicos aparentemente de mesma nomenclatura (v.g. "recurso de revisão"), mas sem a mesma conceituação, sua descontextualização normativa em relação ao restante do funcionamento do sistema jurídico e o absoluto silêncio àquilo que se mencionou no tópico introdutório como "juriscultura". ${ }^{28}$

25 Posição que viria a ser reforçada em texto doutrinário posterior: GRAU, Eros Roberto. Execução antecipada da pena. In: PASCHOAL, Janaína Conceição; SILVEIRA, Renato de Mello Jorge (coord.). Livro homenagem a Miguel Reale Júnior. Rio de Janeiro: G/Z, 2014.

Como, por exemplo, o Pacto Internacional de Direitos Civis e Políticos, adotado na legislação interna brasileira por força do Decreto 591, de 06.07.1992, Art. 14, 2. Toda pessoa acusada de um delito terá direito a que se presuma sua inocência enquanto não for legalmente comprovada sua culpa.

O trecho em questão encontra-se na página 8 do voto do Ministro mencionado e correspondente à página 1104 do processo.

Ao fazer essa menção o Ministro se apoia no trabalho FRISCHEISEN, Luiza Cristina Fonseca; GARCIA, Mônica Nicida; GUSMAN, Fábio. Execução Provisória da Pena Panorama nos ordenamentos nacional e estrangeiro. Revista ANPR Online, n. 7, 2008 o qual, por sua vez, incorre na mesma crítica ao fazer emprego do direito comparado: sua limitação a enumeração de artigos de lei. 


\section{O TERCEIRO MOVIMENTO E A FRAGILIDADE ARGUMENTATIVA}

O terceiro movimento é dado com o julgamento, pelo STF, do HC 126.292 cujo caso fático merece aqui ser destacado. ${ }^{29}$

Com efeito, trata-se de acusação penal pela prática de crime de roubo qualificado imputada a dois acusados quem, inicialmente presos, tiveram a liberdade provisória concedida e aguardaram o julgamento de mérito em liberdade.

Um deles foi condenado à pena de cinco anos e quatro meses; o outro a uma reprimenda maior, de 06 anos e 08 meses. O sentenciado à menor pena, por ser primário, pode apelar em liberdade; o outro teve sua prisão cautelar determinada e ambos recorreram. O Ministério Público não recorreu, pelo que o máximo da pena para ambos já estava determinado.

O TJSP julgou a apelação pouco mais de um ano após o encaminhamento dos autos àquela Corte quando, na apreciação da apelação, as condenações foram mantidas e mesmo o réu primário teve sua prisão decretada. É inegável que esse sentenciado teve sua situação processual piorada com o recurso por ele manejado.

Contra a determinação daquela prisão foi impetrado habeas corpus junto ao STJ, com parecer favorável do MPF à concessão, mas a liminar pretendida foi negada, o que levou à impetração do caso junto ao STF (aqui, o HC $126.292^{30}$ ), tendo a liminar sido deferida pelo então Min. Teori Zavascki reconhecendo a ilegalidade da prisão determinada pelo TJSP.

Submetido ao pleno do STF para análise da liminar concedida naquela Corte, o resultado final foi não apenas o do retrocesso processual no caso concreto, em verdadeiro emprego de um habeas corpus com resultado in malam partem como no retrocesso geral de compreensão da matéria.

Nesse julgado, o então Relator, Min Teori Zavaski, retomou a argumentação precedente a 2009 para afirmar que "Ressalvada a estreita via da revisão criminal, é, portanto, no âmbito das instâncias ordinárias que se exaure a possibilidade de exame de fatos e provas e, sob esse aspecto, a própria fixação da responsabilidade criminal do acusado."

29 Com apoio na descrição feita por STRECK, Lênio Luiz. O estranho caso que fez o STF sacrificar a presunção da inocência. Disponível em https://www.conjur. com.br/2016-ago-11/senso-incomum-estranho-fez-stf-sacrificar-presuncao -inocencia, acessado em 10 de outubro de 2017.

30 BRASIL. Supremo Tribunal Federal. Habeas Corpus 126.292. Relator(a): Min. Teori Zavascki. Julgamento: 17/02/2016. Órgão Julgador: Tribunal Pleno. 
E concluiu: "É dizer: os recursos de natureza extraordinária não configuram desdobramentos do duplo grau de jurisdição, porquanto não são recursos de ampla devolutividade, já que não se prestam ao debate da matéria fático-probatória. Noutras palavras, com o julgamento implementado pelo Tribunal de apelação, ocorre espécie de preclusão da matéria envolvendo os fatos da causa".

Nesse trecho afigura-se, também para o direito interno, uma afirmação de grande perplexidade ao condicionar o duplo grau de jurisdição às espécies de efeitos que determinados recursos possuem, trilhando uma seara interpretativa de rara presença quando se observa, à luz da compreensão do Direito Internacional Público, nas decisões das Cortes protetivas de direitos humanos, as características básicas do que aqui se denomina de "duplo grau".

\subsection{O EMPREGO DA ARGUMENTAÇÃO COMPARADA}

O momento histórico vivido pelas Cortes Superiores, a partir da AP 470, conhecido como "caso mensalão", implica na chegada de inúmeros recursos processuais oriundos de processos de larga repercussão nacional e tratar as prisões existentes como cautelares na esteira do quanto decidido no HC 84.078/MG a partir do primado constitucional implicaria na necessidade de uma resposta processual de mérito em tempo razoável, algo que os Tribunais Superiores parecem não ter condição operacional de ofertar como regra. ${ }^{31}$

O retorno à visão utilitarista contou, no julgado de 2016 acima referido, com um diferencial em relação ao cenário anterior: o uso do comparatismo como forte argumento de autoridade para reverter a compreensão tida como majoritária de 2009.

Essa mesma estratégia de legitimação viria a se fazer presente em 2018 quando foi apreciado o HC 152.752 impetrado com o objetivo de reverter o cenário instalado com o HC 126.292.

Antes de percorrer algumas das manifestações comparadas nestes julgados dado que os limites do presente texto não permitem a análise

31 Ver, para o STF, Joaquim Falcão, Ivar A. Hartmann, Vitor P. Chaves em III Relatório Supremo em Números: o Supremo e o tempo. Rio de Janeiro: Escola de Direito do Rio de Janeiro da Fundação Getulio Vargas, 2014. 151 p. Para o Direito Penal a média de tempo para publicação do acórdão é, na média de 228 dias (cf. p. 73) e pedidos de vista em casos que envolvem esse ramo é de 269 dias (cf. p. 93) 
individualizada de cada ordenamento usado na menção "comparada" é interessante destacar desde um primeiro momento, com Eser, ${ }^{32}$ que, dentre as funções do comparatismo por ele enunciadas não se cogitou do emprego do comparatismo naqueles votos como fundamento para uma revisão legislativa, tampouco de uma conformação teórica harmonizadora do tema, mas sim da pretensão do uso do comparatismo como ferramenta de justificação da racionalidade da decisão.

Distante de qualquer das discussões contemporâneas sobre os desafios metodológicos do comparatismo, dos limites de seu emprego ${ }^{33} \mathrm{e}$ do seu papel na construção de uma estrutura harmonizada de ordenamentos num espaço regional passou-se diretamente, quando da apreciação pela Corte, à menção de artigos de lei de diferentes ordenamentos, unificados, num primeiro momento, apenas pela rotulação "liberal" para alcançar a legitimação para a decisão pessoal adotada.

Tomado o comparatismo como uma reflexão sobre culturas jurídicas, a dizer, desde a produção normativa até a maneira como se dá sua aplicação forense e a forma como a construção doutrinária se produz; o seu emprego nos julgados aqui tratados carece de profundidade posto que nada mais foi "comparado" senão a enunciação de textos normativos e sua justaposição ao texto questionado, na verdade, ao texto que se deseja limitar, a saber, a base constitucional.

E, como aponta precisa observação sobre o uso do comparatismo: "A la hora de interpretar y estudiar el texto extranjero, el comparatista

32 “Two objectives are often clearly discernible in today's comparative jurisprudence: on one hand, the consultation of foreign laws to create national legislation in the spirit of 'legislative comparative law'; and on the other hand, the comparison of differing legal orders for the purpose of better understanding law in the spirit of 'academic-theoretical comparative jurisprudence'. In addition, as already suggested by the civil lawyer Zitelmann at the beginning of this century, there is additional objective for the consideration of a foreign legal system: the comparative study which is necessitated by the application of law in individual circumstances and as such could perhaps be described as judicative comparative law." "ESER, A.; "The importance of Comparative Legal Research for the Development of Criminal Science", Nouvelles Études Pénales. Érès, Paris.1998.

$33 \mathrm{Ou}$ do verdadeiro ceticismo sobre sua dimensão existencial. A este respeito ver DUBBER, M. D. Comparative Criminal Law, in M. Reimann and R. Zimmermann (eds.), The Oxford Handbook of Comparative Law (Oxford University Press, 2006) 
debe entrar en el tejido jurídico de referencia en su globalidad. No debe detenerse únicamente en el contenido proporcionado por la normativa extranjera, sino que debe avanzar y examinar cómo este se amalgama en un único conjunto, incorporando también la doctrina y la jurisprudencia, que, como denomina Sacco, son el 'formante' del derecho. Esta toma de conciencia en su conjunto ayuda al comparatista a comprender la correcta finalidad, eficacia y alcance de la norma que está analizando, consiguiendo que el derecho comparado se convierta en 'anticoncettuale'". ${ }^{34}$

Da análise do emprego denominado de comparatismo nesses julgados tem-se algumas situações destacadas.

Inicialmente, no HC 126.292 além do já evidenciado equívoco da redução do comparatismo a mera menção de artigos de lei, a assimilação do comparatismo a decisões de Cortes Internacionais, estas localizadas no âmbito do Direito Internacional Público. ${ }^{35}$

Nesse mesmo acórdão, e ainda por parte do mesmo Magistrado mencionado, a invocação de ordenamentos pertencentes a tradições jurídicas distintas, v.g. common law (direito estadunidense) ${ }^{36}$ e civil law (direito europeu continental) como se entre eles houvesse simetria e, entre ambos e o direito interno brasileiro plena harmonização.

Na mesma esteira e com os mesmos problemas metodológicos o voto do Ministro Teori ${ }^{37}$ no qual a interpretação normativa é dada per saltum ${ }^{38}$ posto que apoiada em texto singular de direito interno sem

34 FERRANTE, Alfredo. Entre derecho comparado y derecho extranjero: una aproximación a la comparación jurídica. Revista Chilena de Derecho, v. 43, n. 2, p. 601-618, 2016.

35 Assim, por exemplo, no voto do Ministro Gilmar Mendes, especialmente em trecho contido na página 69 do acórdão.

36 Cf. pg. 70 do voto mencionado no sobredito julgado.

37 Cf pg. 12 e seguintes

38 Vide, uma vez mais, o voto já mencionado de Menezes Direito ou o de Teori Zavascki que, após mencionar uma frase isolada da então Min. Ellen Gracie no julgamento do HC 85886 "em país nenhum do mundo, depois de observado o duplo grau de jurisdição, a execução de uma condenação fica suspensa, aguardando referendo da Corte Suprema" (e não localizada no acesso eletrônico constante em <http://redir.stf.jus.br/paginadorpub/paginador.jsp?docTP=AC\&docID=354366 >) passou-se a transcrever trechos de artigo doutrinário sem qualquer inflexão, tomando-se aquele material como portador de afirmações 
que o próprio autor(a) do voto tenha diretamente consultado as bases do direito que se quer empregar a título comparado e sem flexionar o texto nacional empregado com outros tantos da literatura pátria que lhes são contrapostos.

Por sua vez, no HC 152.752 já mencionado ${ }^{39}$ também foram empregadas referências do Direito Internacional Público. ${ }^{40}$ Nesse mesmo acórdão, em um dos empregos do comparatismo foi, por exemplo, invocado o direito alemão, e chegou-se a insistir na interpretação da possibilidade de uma execução provisória, nada obstante a dicção normativa explícita em sentido contrário incidente na matéria. ${ }^{41}$

A posição adotada no julgado, no entanto, não se sustenta a teor da literatura de grande importância e de fácil acesso, pois, como afirma Roxin, "en particular, la cosa juzgada formal tiene importancia por lo seguinte: es pressupuesto de la ejecución (\$449). En contraposición con el proceso civil, en el proceso penal non hay una ejecución 'provisional', esto es, no es posible la ejecución sin cosa juzgada". ${ }^{42}$

inquestionáveis e precisas as quais, como já destacado em nota anterior deste trabalho, também reduz o comparatismo à menção de textos legais.

39 BRASIL. Supremo Tribunal Federal. Habeas Corpus 152.752. Relator Atual: Min. Edson Fachin. Pacte.(S) Luiz Inacio Lula Da Silva. Impte.(S). Cristiano Zanin Martins. Sem julgamento definitivo até o momento em que este artigo foi concluído.

40 Assim, no voto do Min. Fachin, especialmente pgs. 07 e 08, ao mencionar precedentes da Corte Interamericana de Direitos Humanos. Da mesma maneira, e apenas citando artigos de tratados internacionais protetivos de direitos humanos, o voto do Min. Barroso, pp. 10 e 11. Igualmente no voto do Min. Alexandre Moraes, especialmente p. 10 arrimado num trabalho acadêmico singular.

41 HC 126.292 citado, trecho do voto do Ministro Teori Zavascki (Relator) contido na página 14 do acórdão que, por sua vez, reproduz o voto do Ministro Menezes Direito já mencionado.

42 ROXIN, Claus. Derecho procesal penal. Buenos Aires: Editores del Puerto, 2000, p. 435. Da mesma maneira: COLOMER, Juan-Luis Gómez. El proceso penal alemán: introducción y normas básicas. Bosch, 1985, pp 180-181. O uso das referências de textos sobre direito alemão traduzidos para o espanhol é aqui feito para acompanhar o alerta trazido no texto de FERRANTE, Alfredo. Entre derecho comparado y derecho edxtranjero: una aproximación a la comparación jurídica. Revista chilena de derecho, v. 43, n. 2, p. 601-618, 2016. 
Ainda nesse voto também foi empregado o direito italiano para justificar o raciocínio de uma "coisa julgada progressiva" ao ser afirmado que "O modelo italiano tem ainda outra regra bastante interessante, ao admitir a formação progressiva do trânsito em julgado. Havendo uma pena mínima (líquida) já com trânsito em julgado, dá-se início à execução"43 sem, contudo, flexionar que essa possibilidade de execução "progressiva" encontra historicamente posições contraditórias ${ }^{44}$ e mesmo sem amparo em precedentes da própria Corte de Cassação, devendo ser notada que a sobredita progressividade da coisa julgada não autoriza a execução antecipada da pena da forma como pretendida quando, por exemplo, houver a anulação do julgado com determinação de reenvio ao Juízo original ${ }^{45}$.

Contudo, ainda que a parte tida como definitiva diga respeito à pena (hipótese distinta da anteriormente mencionada), há lastro doutrinário suficiente para afirmar que ainda assim não existe a coisa julgada exequível na parte incontroversa: "in caso di annullamento parziale, il giudizio sarà rinnovato solo con riferimento alle disposizioni della sentenza annullate (...) mentre le altre assumeranno il valore di decisione passata in giudicato (che non significa, tuttavia, eseguibilità della sentenza in ordine alle parti non annullate, poiché l'eseguibilità della sentenza di condanna va posta in relazione alla formazione di un vero e proprio titolo esecutivo, mentre l'autorità di cosa giudicata ad una o più

43 HC 152.752, voto do Min. Gilmar Mendes onde se faz menção expressa ao art. 624 do CPP italiano, contida na página 13 do seu voto.

44 LATTANZI, Giorgio; LUPO, Ernesto. Codice di procedura penale. Giuffrè, 2008, p. 579. Para uma abordagem específica sobre o tema, ORLANDI, Renzo. Provvisoria esecuzione delle sentenze e presunzione di non colpevolezza. AA.VV, Presunzione di non colpevolezza e disciplina delle impugnazioni, $\mathrm{Mi}-$ lano: Giuffrè, 2000, p. 123.

45 A ver, por exemplo: Qualora venga rimessa dalla Corte di cassazione al giudice di rinvio la sola determinazione della pena, la formazione del giudicato progressivo riguarda esclusivamente l'accertamento del reato e la responsabilità dell'imputato; pertanto, la detenzione dell'imputato deve essere considerata come custodia cautelare, e non come esecuzione di pena definitiva. (Fattispecie relativa a rigetto del ricorso proposto dal P.G. avverso un'ordinanza di sostituzione della misura cautelare della custodia in carcere con quella degli arresti domiciliari disposta nel giudizio di rinvio). Dichiara inammissibile, App. Firenze, 23/04/2013. Cassazione penale sez. VI 19 dicembre 2013 n. 2324 (sem grifo no original). 
statuizioni contenute nella sentenza di annullamento parziale è correlata esclusivamente all'esaurimento del relativo giudizio): l'autorità di cosa giudicata viene assunta dall'intera res iudicanda, a processo concluso" ${ }^{46}$.

E, como lembra Cordero, o art. 624, n.1, mencionado no voto do STF apenas existirá julgado executável quando a parte ainda pendente de impugnação se fizer agregar daquela já definitivamente decidida não havendo, pois, uma "execução provisória" em sede penal. ${ }^{47}$

\section{Conclusões}

Do breve percurso trilhado observa-se que o emprego do comparatismo nas manifestações do STF sobre o tema do início da execução da pena quando da pendência de recursos gerando a chamada "execução provisória” deu-se com desapego às bases metodológicas contemporâneas do Direito comparado.

Visando ilustrar ou mesmo robustecer de autoridade a posição adotada, desatendeu-se aos primados essenciais da metodologia comparada quando foram invocados ordenamentos jurídicos de tradições distintas, com toda a herança política e cultural que isso significa.

Ainda, sem um próprio método de comparação foram invocados institutos jurídicos sem sua decomposição conceitual nos respectivos ordenamentos, os a serem usados como comparação e o brasileiro, de alguma maneira receptor desses pretensos conceitos.

Desatendido o elementar do método comparado, restou impraticável que se buscasse a essência do comparatismo, que é a análise

46 GAITO, Alfredo. AA.VV, Procedura Penale, Il ricorso per cassazione, Torino: Giappichelli, 2010, pagg. 808 - 809. Em tradução livre: no caso de anulação parcial, o julgamento será renovado apenas no que diz respeito às disposições anuladas da sentença (...) enquanto as demais assumirão a condição de decisão transitada em julgada (o que não significa, contudo, a possibilidade de execução da sentença no que diz respeito às partes não anuladas, dado que exequibilidade da sentença de condenação se faz em relação à formação de um verdadeiro e próprio titulo executivo, ao passo que a autoridade da coisa julgada de um ou mais tópicos contidos na sentença parcialmente anulada diz respeito apenas ao exaurimento daquela parte): a autoridade da coisa julgada diz respeito à integralidade da res judicata, de um processo concluído

47 CORDERO, Franco. Procedura penale, Giuffrè, 2003, p. 795. 
da cultura jurídica em cada um desses ordenamentos restando, pois, a isolada menção a textos normativos e não raras vezes usados de forma questionável mesmo nos ordenamentos dos quais foram extraídos.

Por tal carência de sustentação, em muitos momentos o comparatismo serviu apenas de um lastro argumentativo de autoridade para legitimar a refutação expressa do texto constitucional e, com isso, negar a base constitucional-convencional.

Isso significa, no caso presente, o retorno às bases políticas anteriores à própria reconstrução democrática do Estado brasileiro e reforça, na essência, a construção original do Código de Processo Penal, ele também, por sua vez, fruto de um momento político de exceção ao Estado de Direito e formatador de uma "cultura” processual igualmente autoritária.

\section{REFERÊNCIAS}

BATIA, G. e PIZZO, A. "La tutela dell' imputato -Saggio storico- concettuale", PAULESU, P. P., La presunzione di non colpevolezza dell'imputato, 30, G. Giappichelli, Torino, 2009, p. 30-50.

BRANDÃO, João Pedro Pereira. A execução antecipada da pena nos tribunais superiores brasileiros: os limites da garantia constitucional da presunção de nãoculpabilidade. Revista Brasileira de Ciências Criminais, São Paulo, v. 17, n. 80, p. 150-207., set./out. 2009.

CARVALHO, Luis Gustavo Grandinetti Castanho de. Princípio da presunção de inocência ou da não-culpabilidade. In: CARVALHO, Luis Gustavo Grandinetti Castanho de. Processo penal e constituição: princípios constitucionais do processo penal. 4. ed. Rio de Janeiro: Lumen Juris, 2006.

COLOMER, Juan-Luis Gómez. El proceso penal alemán: introducción y normas básicas. Bosch, 1985.

CONSTANTINO, Giuseppe Luigi Pantoja. Sistema Interamericano de Direitos Humanos: breves linhas sobre a Comissão e a Corte Interamericana de Direitos Humanos. Conteúdo Jurídico, Brasília-DF: 20 dez. 2014.

CORDERO, Franco. Procedura penale, Milano: Giuffrè, 2003.

CRUZ, Peter de, A Modern Approach to Comparative Law, Boston, Kluwer, 1993, p. 15, apud ENRÍQUEZ, David. Interculturalismo y transdisciplinariedad: 
coordenadas en el mapa del derecho comparado sustentable. Boletín mexicano de derecho comparado, v. 44, n. 132, p. 1085-1126, 2011, p. 6.

DAMAŠKA, Mirjan. Aspectos globales de la reforma del proceso penal. Reformas a la Justicia penal en las Américas. www. dplf. org/Fundación para el debido proceso legal, 2000.

DEZEM, Guilherme Madeira. Presunção de inocência: efeito suspensivo dos recursos extraordinário e especial e execução provisória. Revista Brasileira de Ciências Criminais, São Paulo, v. 16, n. 70, p. 269-290., jan./fev. 2008.

DUBBER, M. D. Comparative Criminal Law, in M. Reimann and R. Zimmermann (eds.), The Oxford Handbook of Comparative Law (Oxford University Press, 2006)

ENRÍQUEZ, David. Interculturalismo y transdisciplinariedad: coordenadas en el mapa del derecho comparado sustentable. Boletín mexicano de derecho comparado, v. 44, n. 132, p. 1085-1126, 2011.

ESER, A.; The importance of Comparative Legal Research for the Development of Criminal Science, Nouvelles Études Pénales. Érès, Paris. 1998.

FERRANTE, Alfredo. Entre derecho comparado y derecho edxtranjero: una aproximación a la comparación jurídica. Revista chilena de derecho, v. 43, n. 2, p. 601-618, 2016.

FERRANTE, Alfredo. Entre derecho comparado y derecho extranjero: una aproximación a la comparación jurídica. Revista Chilena de Derecho, v. 43, n. 2, p. 601-618, 2016.

FRISCHEISEN, Luiza Cristina Fonseca; GARCIA, Mônica Nicida; GUSMAN, Fábio. Execução Provisória da Pena Panorama nos ordenamentos nacional e estrangeiro. Revista ANPR Online, n. 7, 2008.

GAITO, Alfredo. AA.VV, Procedura Penale, Il ricorso per cassazione, Torino: Giappichelli Editore, 2010.

GRAU, Eros Roberto. Execução antecipada da pena. In: PASCHOAL, Janaína Conceição; SILVEIRA, Renato de Mello Jorge (coord.). Livro homenagem a Miguel Reale Júnior. Rio de Janeiro: G/Z, 2014.

ILLUMINATI, Giulio. La presunzione d'innocenza dell'imputato. Bologna: Zanichelli, 1984, p. 21.

JOAQUIM FALCÃO, Ivar A. Hartmann, Vitor P. Chaves em III Relatório Supremo em Números: o Supremo e o tempo. Rio de Janeiro: Escola de Direito do Rio de Janeiro da Fundação Getulio Vargas, 2014. 151 p. 
KUEHNE, Maurício. Revisão do decênio da reforma penal: 1985-1995: considerações sobre a execução provisória da sentença penal. Faculdade de Direito de Curitiba, 1995.

LATTANZI, Giorgio; LUPO, Ernesto. Codice di procedura penale. Milano: Giuffrè, 2008, p. 579.

LEGRAND, Pierre. Como ler o Direito Estrangeiro. São Paulo: Editora Contracorrente, 2018, p. 65.

MIRZA, F. Processo Justo: O ônus da Prova à Luz dos Princípios da Presunção de Inocência e do in dubio pro reo. In: Cleber Francisco Alves; Sergio de Souza Salles. (Org.). Justiça, Processo e Direitos Humanos - Coletânea de Estudos Multidisciplinares. 1 ed.Rio de Janeiro: Lumen Juris, 2009, p. 79-96.

MOURA VICENTE, Dário - Direito Comparado - Volume I - Introdução e Parte Geral, Almedina, Coimbra, 2008, p. 19.

ORLANDI, Renzo. Provvisoria esecuzione delle sentenze e presunzione di non colpevolezza. AA.VV., Presunzione di non colpevolezza e disciplina delle impugnazioni, Milano: Giuffrè, 2000, p. 123.

PACKER, Herbert L. Two models of the criminal process. U. Pa. L. Rev., v. 113, p. 1, 1964.

PAULESU, P. P., La presunzione di non colpevolezza dell'imputato, Torino: Giappichelli, Torino, 2009, p. 30-50.

ROXIN, Claus. Derecho procesal penal. Buenos Aires: Editores del Puerto, 2000, p. 435 .

SOUZA, José Barcelos de. Execução provisória de pena privativa de liberdade. Revista Magister de Direito Penal e Processual Penal, Porto Alegre, v. 4, n. 19, p. 42-54., ago./set. 2007.

STRECK, Lênio Luiz. O estranho caso que fez o STF sacrificar a presunção da inocência. Disponível em https://www.conjur.com.br/2016-ago-11/senso-incomum-estranho-fez-stf-sacrificar-presuncao-inocencia, acessado em 10 de outubro de 2017.

SUANNES, Adauto Alonso Silvinho. Podemos falar em execução penal antecipada (jurisprudência comentada). Revista Brasileira de Ciências Criminais, São Paulo, v. 2, n. 7, p. 167-173., jul./set. 1994. 


\section{Informações adicionais e declarações dos autores (integridade científica)}

Declaração de conflito de interesses (conflict of interest declaration): o autor confirma que não há conflitos de interesse na realização das pesquisas expostas e na redação deste artigo.

Declaração de autoria e especificação das contribuições (declaration of authorship): todas e somente as pessoas que atendem os requisitos de autoria deste artigo estão listadas como autores; todos os coautores se responsabilizam integralmente por este trabalho em sua totalidade.

Declaração de ineditismo e originalidade (declaration of originality): o autor assegura que o texto aqui publicado não foi divulgado anteriormente em outro meio e que futura republicação somente se realizará com a indicação expressa da referência desta publicação original; também atesta que não há plágio de terceiros ou autoplágio.

\section{Dados do processo editorial}

(http://www.ibraspp.com.br/revista/index.php/RBDPP/about/editorialPolicies)

- Recebido em: 17/07/2018

- Controle preliminar e verificação de plágio: 21/07/2018

- Avaliação 1:07/08/2018

- Avaliação 2: 22/07/2018

- Avaliação 3: 01/08/2018

- Avaliação 4: 26/07/2018

- Avaliador 5: 31/07/2018

- Decisão editorial preliminar: 17/08/2018

- Retorno rodada de correções: 12/09/2018

- Decisão editorial final: 22/09/2018
Equipe editorial envolvida

- Editor-chefe: 1 (VGV)

- Editores-associados: 2 (FC e BC)

- Editor-assistente: 1 (TACJ)

- Revisores: 5 


\section{COMO CITAR ESTE ARTIGO:}

CHOUKR, Fauzi Hassan. A leitura do STF sobre o sistema recursal e o início da execução da pena: a pauperização do comparatismo à brasileira. Revista Brasileira de Direito Processual Penal, Porto Alegre, vol. 4, n. 3, p. 1119-1142, set/dez. 2018. https://doi.org/10.22197/rbdpp.v4i3.177 